\title{
Two phase motor fed from controlled supply
}

\author{
H. Shousha, Sara Ali, A. B. Kotb \\ Al-Azhar University, Egypt
}

\begin{tabular}{l}
\hline Article Info \\
\hline Article history: \\
Received Aug 17, 2019 \\
Revised Oct 06, 2019 \\
Accepted Oct 31, 2019 \\
\hline
\end{tabular}

\section{Keywords:}

Controlled Supply

The phase voltage values

The sequence

Two phase motor

\begin{abstract}
Compared to single phase operation, a good utilization of machine material is achieved by supplying the two-phase stator windings from a controlled supply. It is necessary to start from the known equivalent circuits of both forward and backward components to obtain the relations between the sequence and the phase voltage values. In this method of control, the torque expression is driven in a simple form and the torque speed characteristic are computed and plotted for different values of the time-phase angle. The operation of 2-phase motor from single phase supply carried out by connecting one stator phase directly to the voltages source, with exciting the second stator phase through the phase shifting element. In this method, the starting and the maximum torque values can be controlled by changing the stator field from a pulsating of $(0 \mathrm{o})$ to a pure rotating field at $(90 \mathrm{o})$.
\end{abstract}

This is an open access article under the $\underline{C C B Y-S A}$ license.

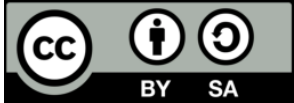

\section{Corresponding Author:}

H. Shousha,

Al-Azhar University, Egypt.

Email: h.i.shousha@gmail.com

\section{INTRODUCTION}

Minimum calculation effort for the two-phase stator currents and the motor electromagnetic torque acting on the rotor are determined. This calculation is carried out, using the time phase angle as parameter. In addition to the conventional two-phase applications, the phase angle control $(2,3)$ will lead to more development of this modified motor. The gradual change of this motor speed can be achieved by controlling the time phase angle between the voltages of the stator windings [1]. Keeping the two-phase voltages with equal in magnitudes enables better utilization of the machine materials.

The use of the two-phase stator windings with phase-angle control leaving the 2-phase voltages equal in magnitudes, leads to better utilization of the machine material [2]. Single-phase motors with main and auxiliary stator windings are widely used, but their extension into symmetrical two-phase enables higher rating range for the same motor design [3-4]. This also, allows good starting conditions and higher maximum torque. The operation of 2-phase motor from single phase supply carried out by connecting one stator phase continuously to the voltages source, and exciting the second phase through a phase shifting circuit.

In order to completely describe the motor performance for a given phase angle control, it is necessary to derive an expression for the stator currents and the motor torque. By using the method of symmetrical components, the unbalanced stator phase voltages are expressed into two balanced components with positive and negative sequence values. Consequently, the forward and backward current components which enable the motor performance can be determined. The characteristics are calculated and plotted for different values of the phase angle between the two-phase voltages. 


\section{OPERATION OF TWO-PHASE MOTOR FROM CONTROLLED SUPPLY}

Compared to single phase operation, a good utilization of machine material is achieved by supplying the two-phase stator windings from a controlled supply. The conventional single-phase induction motor contains two stator windings, the main winding and the auxiliary winding [5]. A capacitor is placed in series with the auxiliary winding, thus nearly, a difference phase angle between the two currents is obtained. Finally after start the single phase motor runs depending only on the main winding. Since this is being single-phase, some level of humming noise is associated with motor during the running.

To run this single-phase induction motor from two-phase supply, modification must be done [6-7]. Capacitor and centrifugal switch are then not needed, and they are cut off through the operation. The auxiliary windings of this modified motor has the same coil diameter and phase turns as well as the main phase windings. In the modified two-phase motor, the windings will completely have a new design to be symmetrical two-phase windings which can be suitable for two-phase motor operation [8]. Figure 1, gives the modification of single-phase motor to be two-phase induction motor [9]. Normally, a variable two phase voltage, variable frequency supply can be obtained from a single phase two phase inverter to feed the modified motor with controlling its speed.

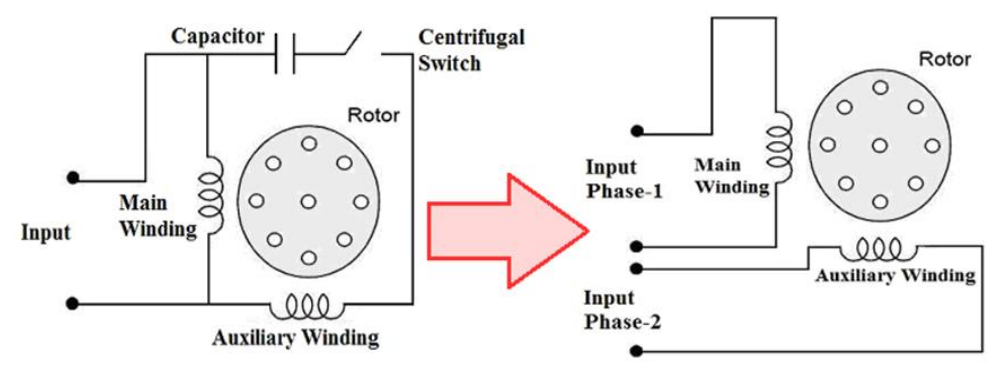

Figure 1. Conversion of single phase to be two phase motors

\section{MATHEMATICAL ANALYSIS AND MOTOR PERFORMANCE UNDER CONTROLLED SUPPLY}

In order to completely describe the motor performance under general operating conditions of unbalanced supply voltage, it is necessary to use equivalent circuit obtained for forward and backward system. The resulting current Is1 and Is2 in the first and second stator phase windings produce magneto motive forces, which are proportional to Is1Ws1 and Is $2 \mathrm{Ws} 2$, respectively. By using the shown equivalent circuit of Figure 2 and the method of symmetrical components, the motor performance can be obtained. The unbalanced stator phase voltages are resolved into two balanced components, the positive and negative sequence values. Consequently, the forward and backward current components, which enable the motor performance are determined.

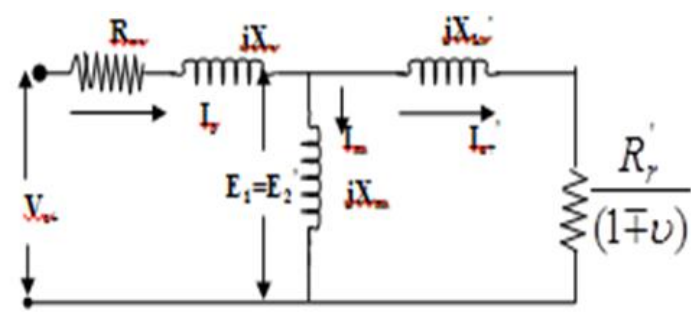

Figure 2. Equivalent circuit of unsymmetrical two phase induction motor

\subsection{The mathematical analysis}

Since, the method of time phase control is used, the second phase voltage V2 is related to the first phase voltage V1 with a time phase angle $\beta$ as (1):

$$
\mathrm{V}_{2}=\mathrm{V}_{1} \mathrm{e}^{-\mathrm{j} \beta}
$$


Starting from the obtained equivalent circuit of Figure 2, it enables now the calculations of the motor currents, the torque and the efficiency, for the values of the phase angle $\beta$. The expressions of positive and negative sequence current components can be written as (2-3):

$$
\begin{aligned}
& \text { Isf }=(V 1+j V 2) / 2 Z f \\
& I s b=(V 1-j V 2) / 2 Z b
\end{aligned}
$$

Where $\mathrm{Zf}$ and $\mathrm{Zb}$ are the positive and the negative sequence impedances given from Figure 2. Therefore, the stator phase currents can be obtained (4-5).

$$
\begin{aligned}
& \text { Is } 1=(\mathrm{V} 1 / 2)[(1+\sin \beta+\mathrm{j} \cos \beta) / \mathrm{Zf}+(1-\sin \beta-\mathrm{j} \cos \beta) / \mathrm{Zb} \\
& \text { Is } 2=(\mathrm{V} 1 / 2)[(1+\sin \beta+\mathrm{j} \cos \beta) / \mathrm{Zf}-(1-\sin \beta-\mathrm{j} \cos \beta) / \mathrm{Zb}]
\end{aligned}
$$

\subsection{The calculated and plotted results}

The calculations were carried out on a motor having the following parameters:

$$
\mathrm{V} 1=220 \mathrm{v}, \mathrm{f}=50 \mathrm{~Hz}, \mathrm{Rs}=3 \Omega, \mathrm{Xs} 1=5.5 \Omega \text { and } \mathrm{Xm}=75 \Omega \text {. }
$$

The two phase stator windings are identical, and the stator phase currents are calculated. The results of the control current are plotted as function of the relative speed $v=n / n s$, or the motor slip $s$ with different value of dimensionless signal coefficient $\mathrm{a} 1=\sin (\beta)$, in Figure 3 , with using the phase angle $\beta$ as parameter.

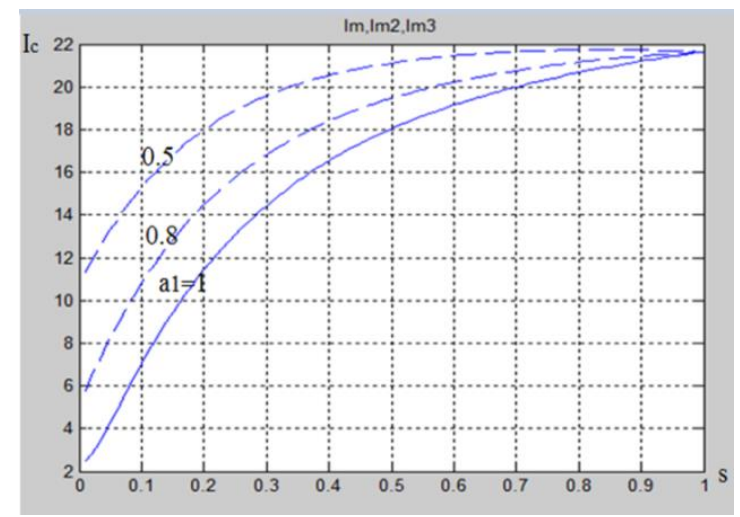

Figure 3. The stator phase current as function of slip

It is clear from the results, that the stator phase current Ic, has different values, while its maximum value obtained at only $\beta=\pi / 2$ at rotating field. It is evident that the small losses is obtained here and the corresponding high efficiency occurs when the field is a pure rotating. The stator phase currents are known, then the electric loading may be determined and the motor performance characteristics can be obtained. The air gap power transferred from the stator to the rotor can be given (6).

$$
\mathrm{Pg}=2\left[\mathrm{I}_{\mathrm{rf}}^{2}\left(\mathrm{R}_{\mathrm{r}} / \mathrm{s}\right)-\mathrm{I}_{\mathrm{rb}}^{2} \mathrm{R}_{\mathrm{r}} /(2-\mathrm{s})\right]
$$

With Irf, Irb are the forward and backward components of the rotor currents. The electromagnetic torque may be then expressed as (7):

$$
\mathrm{T}=\mathrm{P}_{\mathrm{g}} /(2 \pi \mathrm{f} / \mathrm{p})
$$

The developed torque is calculated and plotted as function of the relative speed $v$ or the slip $\mathrm{s}$ in Figure 4 , with different value of coefficient $\mathrm{a} 1=\sin (\beta)$, for the phase angle $\beta$ is taken as parameter. It is evident that the phase angle control gives a wide control range for the motor developed torque where $\beta$ changes from 900 to 0.00 . The intersections of the constant load torque lines with the developed torque 
curves, can be determine the motor speed as function of the phase angle $\beta$. Figure 4 . Shows the motor developed torque as a function of the slip. Higher starting torque ranges are obtained by changing the field from pulsating into an almost rotating field, by increasing the phase angle. It is noted that, the reduction in the phase angle control is carried out to obtain a gradual changes in the speed. This is associated with some reduction in the pullout torque which limits the value of rated load torque.

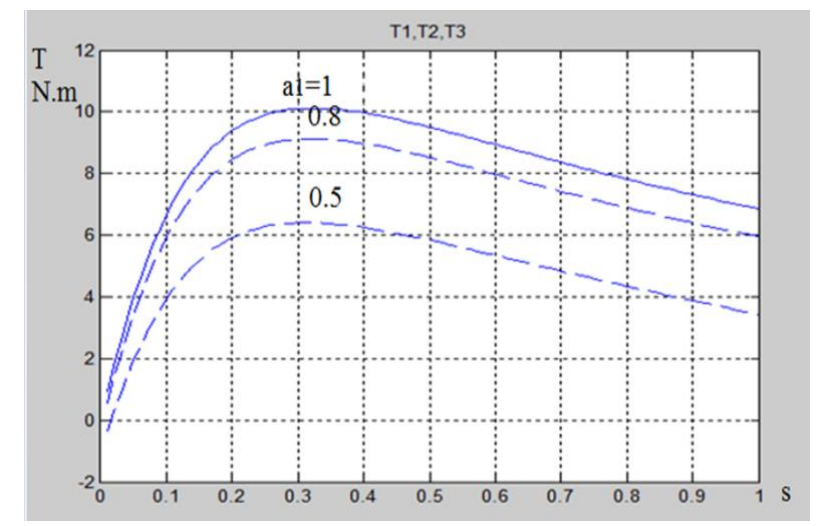

Figure 4. The torque-slip characteristics with $\beta$ as parameter

\section{CONCLUSION}

The better utilization of the motor materials, during all operating conditions can be achieved by operating the single phased motor as two-phase from controlled supply. The control method is carried out here by using phase angle between the two phase stator voltages. The speed and the starting torque in a two-phase I.M can be changed over a wide range.This may be carried out by changing the stator field from pure rotating field at the phase angle $\beta=\pi / 2$ to a pure pulsating field at $\beta=0.0$. The higher starting torque, maximum torque and efficiency are realized with the rotating field operation. The obtained results are given by using the simplified analysis which expressed the controlled current and torque formulas in simple forms. In order to insure a suitable speed control and a large over load capacity the phase angle must be $\pi / 2$ i.e with pure rotating field. This can be achieved only when the modified motor is supplied from an inverter of output perpendicular two-phase voltages.

\section{REFERENCES}

[1] A. B. Kotb: "The effects of secondary sheet design on the performances of sleeve rotor induction motor," AEC.1. Vol. 9, 1989, PP.47-55.

[2] M. Shalaby, "Phase-angle control of the repulsion/drive force ratio in two-phase linear induction motor with nonferromagnetic secondary," in IEE Proceedings B-Electric Power Applications, vol. 132, no. 2, pp. 81-86, March 1985.

[3] M. A. Saleh, M. A. Shehata: "Effect of method of control on the transfer function parameters of a two-phase servo motor," Measurement and control, vol.6, December, 1973, pp.517-524.

[4] Akram H. Ahmed, Ayman M. Ali, "Comparison Between Fuzzy Logic and PI Control for the Speed of BLDC Motor," Vol. 9, No.3 September 2018, pp 1116 -1123

[5] Ayman M. Ali, Salama Abo Zaid, Akram H. Ahmed, "Modified single phase induction motor fed from the solar energy," Journal of engineering and applied sciences, 2018, Vol. 13, issue 16, pp: 6904-6909.

[6] Godbole, P. and A. Y. Fadnis, 2017, "Inverters for two phase induction motor. Proceeding of the 2017 international conference on power and embedded drive control (ICPEDC)," March 16-18, 2017, IEEE, Chennai, India, ISBN:978-1-5090-4679-9,pp:484-489.

[7] F. A. A. Zaher, "An analytical solution for the field of a hysteresis motor based on complex permeability," in IEEE Transactions on Energy Conversion, vol. 5, no. 1, pp. 156-163, March 1990.

[8] A. B. Kotb, M. Shalaby: “Analysis of the disk rotor I.M.," AMSE confer. Vol. 2c, 1987, pp. 73-86.

[9] Rungwicha Chaiyot, Vijit K., Supat K., "Comparison of vector control of Two-Phase Induction motor using continuous and discontinuous SVPWM,” International Electrical Engineering Congress, Pattaya, Thailand, pp. 1-4, March 2017. 